\title{
La construcción del acontecimiento en la era de Internet
}

\section{POR SILVIA TABACHNIK}

silvia.tabachnik@gmail.com Universidad Autónoma Metropolitana (UAM), México

Fecha de recepción: 26/9/2016

Fecha de aceptación: 9/10/2016

\section{RESUMEN}

Se parte de la hipótesis según la cual en el régimen de Internet se están produciendo cambios radicales que afectan la génesis, morfología, modos de representación, circulación y reconocimiento del acontecimiento. Dichas mutaciones incidirían en los modos en que son colectivamente vividos, interpretados los sucesos que conforman la representación mediática de la actualidad. Aquí se propone una “incursión” en los archivos virtuales de Internet con el fin de revisar algunos documentos en video relacionados con el procesamiento mediático de los eventos de Ayotzinapa, un suceso reciente que demanda ser reconocido con la entidad y el estatuto histórico, político y ético de un acontecimiento.

PALABRAS CLAVE: Acontecimiento, actualidad, testimonio, archivo, Internet.

\begin{abstract}
It stems from the hypothesis that radical changes are occurring in the Internet that affect the genesis, morphology, modes of representation, diffusion and acknowledgement of the event. Said mutations would affect the ways in which events of the media representation of the present are collectively experienced and interpreted. This work "delves" into Internet's virtual files to examine videos related to the processing of the events that took place in Ayotzinapa, a recent affair that demands to be acknowledged with the identity and the historical, political and ethical status of an event.
\end{abstract}

KEY WORDS: Event, the present, testimony, archive, Internet. 


\section{PREFACIO}

La noche del 26 de septiembre de 2014, estudiantes normalistas de la Escuela Normal Rural Isidro Burgos de Ayotzinapa (Iguala, Guerrero, en México) requisaron unos autobuses con la intención de viajar ala Ciudad de México para participar en la conmemoración de los Acontecimientos de Tlatelolco (1968). Los estudiantes fueron atacados violentamente por policías municipales: 43 fueron detenidos. Hasta la fecha, se desconoce su paradero.

El nombre Ayotzinapa induce a repensar la noción misma de acontecimiento, recuperarla más allá y a contrapelo de las narrativas mediáticas que tienden a neutralizar su singularidad, asimilándola en la corriente continua e indiferenciada de los eventos del día a día. Desde una perspectiva en la que convergen y divergen fundamentos de la socio-semiótica (de los medios) y del análisis del discurso, lo que se pretende describir y analizar aquí tiene que ver precisamente con ciertas estrategias implementadas por el poder mediático en el procesamiento de los ominosos sucesos ocurridos en Iguala. Se trata de describir y analizar operaciones que responden a una intervención estratégica general orientada, ya no a "construir el acontecimiento", como decía Verón en los años 80, sino a conjurarlo como tal, es decir, a desactivar su impacto y neutralizar su trascendencia política, convirtiéndolo en un episodio más de la narco-telenovela cotidiana.

\section{LA FUERZA DE INTERPELACIÓN DEL ACONTECIMIENTO}

Ante todo cabe precisar que, tal como aquílo concebimos, el acontecimiento no es el suceso noticioso impactante, reportadoy construido "artefactualmente" por las narrativas mediáticas según la lógica sensacionalista del espectáculo, sino aquello-aun innombrado-que surge imprevistamenteen la escena pública e introduce un desajuste, una fisura en las representaciones de la actualidad y del presente, como tiempo de la experiencia colectiva. Un acontecimiento no es del orden de los "hechos" ni de las "evidencias": su materialidad es la de los relatos, las imágenes, las crónicas y, sobre todo, los testimonios que lo nombran, lo convocan y lo actualizan en una multiplicidad de dispositivos.

El punto de partida obligado en vistas a una definición conceptual del acontecimiento consiste en deslindarlo de su identificación con el orden empírico de los hechos. Así lo establece Foucault en "El orden del discurso", cuando ensaya una definición del acontecimiento a través de la negación:

No es ni sustancia, ni accidente, ni calidad, ni proceso; el Acontecimiento no pertenece al orden de los cuerpos. Y sin embargo no es inmaterial; es en el nivel de la materialidad como cobra siempre efecto, que es efecto; tiene su sitio, y consiste en la relación, la coexistencia, la dispersión, la intersección, la acumulación, la selección de elementos materiales; no es el acto ni la propiedad de un cuerpo; se produce como efecto de y en una dispersión material (2004, p. 57). 
También en el artículo "Nietzsche, la genealogía, la historia” (1979), Foucault advierte que la noción nietzscheana de acontecimiento se contrapone a eso que suele llamarse los "grandes sucesos históricos". En este texto Foucault ofrece-también por vía negativa- una definición particularmente sugerente:

Acontecimiento -entendiendo por tal no una decisión, un tratado, un reino o una batalla-, sino una relación de fuerzas que se invierte, un poder que se confisca, un vocabulario recuperado y vuelto contra los que lo utilizan, una dominación que se debilita, se distiende, ella misma se envenena, y otra surge, disfrazada (1979, p. 20).

En contraste con los grandes sucesos dignos de ser registrados por la historia clásica (batallas, guerras, revoluciones), Foucault identifica el acontecimiento a partir de la aparición de ciertos indicios ("efectos materiales") que -mirados en retrospectiva- denunciarían sutiles alteraciones y desplazamientos en el juego de las relaciones de fuerza, indicios por lo general imperceptibles, ilegibles, desde el presente de actualidad.

Otra vertiente dela aproximación foucaultiana a la problemática del acontecimiento se manifiesta a partir de su relectura del texto de Kant (Foucault, 1996). Foucault vuelve a abordar la cuestión del acontecimiento aquí en la perspectiva de una ontología del presente y despliega la pregunta kantiana por la Ilustración en una serie de interrogantes que serían la condición de posibilidad para establecer un diagnóstico del presente. Éste es, en nuestra lectura, un aspecto crucial de la teoría foucaultiana del acontecimiento, precisamente porque estos interrogantes son los que definen y distinguen al acontecimiento como tal. Y son también estas mismas interrogantes las que desestabilizan y desnaturalizan las estrategias mediáticas orientadas a "conjurar" el acontecimiento: “QQué está ocurriendo en este preciso momento?, ¿Qué nos está sucediendo? ¿Cuál es el mundo, el período, este preciso momento en que estamos viviendo?" (Foucault, 1995, p. 175).

Así, el acontecimiento nombrado Ayotzinapa no puede responder a estas preguntas, pero no cesa de formularlas despertando incesantemente su poder de interpelación. En conclusión: el acontecimiento se definiría por la índole de los interrogantes que suscite y esos interrogantes, por su naturaleza deíctica, se actualizan en actos singulares de enunciación. Además estas preguntas son incancelables porque carecen de respuestas conclusivas. Enunciada en primera persona del plural y en tiempo presente, esas preguntas nos conciernen y nos interpelan. Y es precisamente esta fuerza y ese poder de interpelación la condición distintiva del acontecimiento, lo que permite reconocerlo como tal y deslindarlo de los sucesos ordinarios de la actualidad mediática. 


\section{LA CONJURA DEL ACONTECIMIENTO Y LA ARTEFACTUALIDADMEDIÁTICA}

La conjura del acontecimiento no sería pues, según nuestra hipótesis, el efecto de una operación de "manipulación" mediática (según los remanidos enfoques deterministas o mecanicistas), sino el producto de la común índole doxástica (Angenot, 1982;1989) que comparten los ideologemas de los relatos mediáticos con los topoi que nutren las conversaciones y discusiones en las redes sociales. En su gestación, el acontecimiento resulta procesado y modelado según esquemas de descripción, comprensión e interpretación que gozan de aceptabilidad y consenso mayoritario.

Bajo la hegemonía mediática la actualidad deglute el acontecimiento y lo procesa según diferentes operaciones: disociándolo de su vinculación histórica y política con el paradigma de acontecimientos presentes y pasados en que, por fuerza y efecto de la memoria colectiva, resulta inscrito; o cancelando su singularidad y asimilándolo en el paradigma de eventos supuestamente homólogos que conforman las diferentes narrativas de la violencia (entre ellas, las de la delincuencia organizada, los genocidios, los feminicidios, las desapariciones forzadas, la trata de personas).

La primera operación deshistoriza el acontecimiento y la segunda lo despolitiza. Sin embargo, a la luz de las nuevas tecnologías es preciso relativizar la incidencia de los medios electrónicos tradicionales en la construcción de las representaciones sociales. Ya no son los mass media los que detentan el monopolio de la historia y la propiedad exclusiva sobre el acontecimiento, como diagnosticaba Pierre Nora (1985) en "La vuelta del acontecimiento". Si bien su incidencia sigue siendo incuestionable en la tecno-cultura contemporánea, su intervención se encuentra, si no neutralizada, al menos amortiguada por la irrupción de las nuevas tecnologías, que han expandido y diversificado inusitadamente el acceso inmediato a la información.

La Red -con los diferentes dispositivos y recursos técnicos que ofrece a los usuarios- parece haberse constituido en el espacio privilegiado (más aún, en la condición de posibilidad) para la producción, puesta en circulación y reapropiación social de los eventos que conforman el escenario de lo que reconocemos en términos de la artefactualidad, neologismo que propone Derrida para aludir a la "hechura ficcional de la actualidad, la cual no está dada sino activamente producida, cribada, investida, performativamente interpretada por numerosos dispositivos ficticios o artificiales, jerarquizadores y selectivos" (1998, p. 15).

Así la instancia fundamental en la génesis del acontecimiento, que es la de su reconocimiento, demandaría entre otras intervenciones el desmontaje de los presupuestos de los relatos consensuados y concluyentes (y aun los inconclusos) institucionalmente legitimados (mediáticos y oficiales), así como la desarticulación del régimen de verosimilitud que los sustenta asimilando y 
disimulando incongruencias e inconsistencias. Pero, sobre todo, demandaría el abordaje crítico de los distintos dispositivos de enunciación que intervienen en la gestación del acontecimiento, fijando los lugares y las condiciones establecidas para la apropiación autorizada de la palabra.

\section{OPINIÓN, TESTIMONIO Y PARRESÍA}

Las redes sociales pueden incidir de manera decisiva, ya sea en la validación del régimen consensual de verosimilitud o, en caso contrario, en su desmontaje, actuando - en su vertiente crítica-como una suerte de dispositivo de procesamiento de la actualidad e implementando estrategias de refutación que corroen los fundamentos de la versión oficial. Por lo que concierne a los videos testimoniales "archivados" en la Red bajo el rótulo de Ayotzinapa, precisamente por el régimen de verdad que les es propio, no pueden ser por completo absorbidos en la trama conversacional de las redes, aún si la nutren de opiniones y comentarios.

Esos testimonios demandan ser abordados como prácticas de veridicción inmersas en un régimen conversacional que las altera y las somete a otras lógicas y otros contratos. Habría un desajuste entre el orden de veridicción propio del testimonio -enunciado siempre en tiempo presente y en primera personay el dominio de la doxa -de enunciación colectiva y anónima- que impera en los discursos mediáticos, prolifera en las redes sociales y se reproduce también en los "sistemas de comentarios" que acompañan los videos testimoniales.

No se trata aquí de sostener que las prácticas veridictivas del testimonio opondrían "la" verdad (la del sobreviviente) a una falacia (la del relato oficial y la de las versiones mediáticas). La cuestión no se dirime entre lo verdadero o lo falso: lo que ocurre es que los testimonios de los sobrevivientes introducen otro régimen de veridicción y entre las dos lógicas -la del testimonio y la de la doxa-habría una suerte de incompatibilidad congénita: son dos "juegos de lenguaje" incomparables porque la experiencia del sobreviviente (como lo han enseñado los testimonios de los campos de exterminio, y también los de los sobrevivientes de los centros clandestinos de detención en Argentina (Tabachnik, 1999) es literalmente inconmensurable: no se puede medir con la vara de la verosimilitud ni con el peso de las evidencias científicas.

Reconocemos la verdad propia del testimonio en el régimen de la parresía, según la definiera Foucault en sus estudios sobre las prácticas de veridicción entre los filósofos presocráticos. Es decir:

Una clase de actividad verbal donde el que habla tiene una relación específica con la verdad a través de la franqueza, un cierto tipo de relación consigo mismo o con otras personas a través de la crítica (autocrítica o crítica a otras personas), y una específica relación con la ley moral a través de la libertad y el deber (2004, p. 27). 
La parresía es del orden de la veridicción, pero la verdad que persigue no es la de alguna adecuación con los hechos en sí, sino la verdad que está sostenida por la posición ética de un sujeto: la verdad que se sustenta asumiendo un riesgo por guardar -citando la sugestiva expresión de Badiou (1995, p. 147)"fidelidad al acontecimiento".

Reproduzcamos ahora parte del testimonio de un sobreviviente de Ayotzinapa en una entrevista realizada el 10 de noviembre de 2014, en las instalaciones de la Heroica Normal:

Lo que sucedió en Iguala, claro que me deja marcado, algo que muy difícilmente se puede superar... a mí me han preguntado que si soy valiente o por qué sigo aquí en la Normal, yo les he dicho que tengo miedo, pero les he dicho que la valentía no es la ausencia del miedo sino el triunfo sobre él, y el miedo me ha orillado y me va a orillar a actuar, porque no solamente tengo miedo... tengo más coraje que miedo, tengo más rencor que miedo... tengo más resentimiento que miedo... tengo más odio y desprecio contra lo que está aconteciendo ${ }^{1}$.

Es en este horizonte y en esos términos donde nos proponemos pensar la problemática del testimonio como práctica de veridicción que cobra efecto y sentido en tanto se constituye no como relato supuestamente verídico, científicamente comprobado, objetivamente apegado a los hechos, sino como un acto de habla que asume el valor y la eficacia de una denuncia pública formulada en tiempo presente y en el plural de la primera persona. El acontecimiento se enuncia en el régimen del testimonio y en la voz del testigo y se funda en un compromiso ético del sujeto con la verdad que profesa.

El régimen de anonimato generalizado que impera en Internet y que en cierta medida exime a los sujetos de responsabilidad sobre sus dichos (Tabachnik, 2006), instaura una especie de zona franca para la proliferación de las opiniones y las controversias, rozando el territorio de la injuria, el insulto y la diatriba. Además, se trata de un anonimato de doble sentido: concierne tanto a la instancia de enunciación como a la de destinación pública y abierta de los mensajes; el destinatario es tan anónimo como el destinador. Ambos carecen de nombre y de señas de identificación.

De modo que los comentarios son intervenciones sin consecuencia ni riesgo. El sujeto de la opinión sería la contrafigura del parresiastés: resguardado en el anonimato o bajo seudónimo el sujeto no corre riesgo ni asume compromiso alguno en relación con sus dichos.

\section{OPERACIONES YESTRATEGIAS MEDIÁTICAS}

En cuanto al concepto de estrategias al que hacemos referencia en este contexto, se remite a la definición foucaultiana que las analiza como "intencionales y a la vezno subjetivas”; esto es, como «grandes estrategias anónimascuya racionalidad

1 Recuperado de https://www.youtube.com/watch?v=PoX5pFuhIt0 
está en las tácticas que, al interrelacionarse, constituyen dispositivos de conjunto" (Foucault, 1987, p. 69). Asimismo, Foucault subraya el "carácter implícito de las grandes estrategias anónimas, casi mudas, que coordinan tácticas locuaces cuyos inventores o responsables frecuentemente carecen de hipocresía" (1987, p. 69).

Estas precisiones son particularmente pertinentes y esclarecedoras para un análisis de las estrategias mediáticas como el que aquí proponemos realizar, sobre todo cuando Foucault puntualiza y advierte que:

No hay poder que se ejerza sin una serie de miras y objetivos, eso no significa que resulte de la opción o decisión de un sujeto individual (...) No busquemos el estado mayor que gobierna su racionalidad, ni la casta que gobierna, ni los grupos que controlan los aparatos de Estado, ni los que toman las decisiones económicas más importantes (1987, p. 114).

En lo que concierne al concepto de "operaciones", éste se inscribe en el horizonte de la sociosemiótica veroniana (Verón, 1988; 1993). Como explica Bitonte (2007), en "La semiosis social. Fragmentos de una teoría de la discursividad", la noción de operaciones aparece como un concepto metodológico:

Las relaciones de un discurso con sus condiciones de producción y reconocimiento se pueden representar de manera sistemática en forma de gramáticas, en la medida en que éstas describen las operaciones de asignación de sentido de las materias significantes (...) - por tanto- la noción de operaciones remite a la relación entre el discurso y sus condiciones sociales e históricas (Bitonte, 2007, p. 2).

En el análisis del proceso de desactivación del acontecimiento nos interesa centrarnos en las estrategias y las operaciones retóricas orientadas a establecer una versión verosímil y mayoritariamente consensuada de los sucesos en cuestión, entendiendo que este procedimiento (esta intervención) produce efectos de neutralización de la singularidad del acontecimiento, despojándolo de su potencia disruptiva. La dimensión trágica del mismo resulta banalizada en una lectura donde prima la apelación al pathos.

\section{ESTRATEGIAS DE NARCO-CRIMINALIZACIÓN}

En el México actual, tanto en el discurso oficial como en el imaginario colectivo, la narco-delincuencia: el "mundo" narco con toda la constelación de significantes verbales y visuales que convoca (Tabachnik, 2014), domina de manera prácticamente excluyente el horizonte de interpretación delos eventos nefastos que componen el presente.

Así, cada episodio de conflicto y violencia que se apropie a su turno de la escena pública, cualquiera que sea su naturaleza (movilizaciones sindicales, campesinas, estudiantiles, de diferentes minorías), resultará asimilado de manera más o menos oblicua o francamente incriminatorias, en el discurso mediático oficial, con la "narco-delincuencia" como horizonte privilegiado 
de interpretación. Valga de muestra una columna política publicada el 14 de septiembre de 2015 en El Universal:

En el caso de Iguala, en Guerrero, parece claro que si el móvil del crimen hubiese sido político no habría sido necesario matar a medio centenar de personas; tampoco martirizarlas como lo hicieron los matarifes especializados en causar dolor y miedo. Un mensaje político no requiere de terror y menos de barbarie. También parece claro que si se trató de un intento por calentar la plaza (...) el resultado fue distinto, más que calentar la plaza la incendiaron.

Pero aparece una duda clave a la que pocos han puesto atención. ¿Qué hacían en Iguala un centenar de estudiantes de la Normal de Ayotzinapa, si su centro de influencia y activismo está en la capital, Chilpancingo? ¿Por qué secuestrar autobuses en Iguala si los pudieron secuestrar en la capital del estado, en la autopista, en otros municipios?

Una pista que podría ser la punta de la madeja es que líderes de los normalistas podrían estar involucrados con grupos criminales adversarios a los Guerreros Unidos. Y el móvil del crimen colectivo podría ser un ajuste de cuentas entre bandas del narcotráfico. Y los jóvenes serán el mensaje. Al tiempo².

No nos detenemos en el análisis del texto citado. Su naturaleza doxástica, según lo definía Angenot (1982), resulta patente así como la condición lacunaria de su argumentación y el recurso a clichés y antítesis estereotipadas. Aunque sí nos valdremos de los conceptos y categorías propuestas por el mencionado Angenot, ya que resultan particularmente idóneos para abordar este texto, ejemplarmente entimemático y particularmente representativo de una corriente de opinión (la coartada del narco) que, sin consagrarse como la versión oficial, interviene sottovoce y aflora periódicamente en las crónicas mediáticas y en las conversaciones en redes sociales.

La conversión retórica delas víctimas en narcodelincuentes esla más básica de las estrategias, tal vez la de mayor eficacia y la de resultados más inmediatos: consiste en equiparar el acontecimiento Ayotzinapa a un episodio más -otro "ajuste de cuentas" entre bandas- en la larga serie de la guerra entre organizaciones del narco por el control de territorios. Ahora bien: la conversión en términos y principios de verosimilitud, topos, entimemas, lugares comunes y clichés, es al mismo tiempo una eficaz estrategia de conjura del Acontecimiento en tanto lo reduce o traduce en el lenguaje "universal" de la doxa.

La estrategia de referirlo al horizonte omni-interpretativo del narco según la figura reconocible de un "ajuste de cuentas" verosimiliza el acontecimiento: lo desactiva neutralizando aquello que no puede explicarse en términos del "sentido común". Y porque se trata efectivamente de un acontecimiento (nombrado Ayotzinapa), hay un núcleo resistente que es irreductible al sentido común, al orden de las opiniones consensuadas que no puede ser digerido por los dispositivos verosimilizantes de la doxa.

2 Itinerario en El Universal. Recuperado dehttp://www.eluniversal.com.mx/entrada-de-opinion/columna/ricardoaleman/nacion/2015/09/14/los-43-los-mataron-por-narcos 
Tampoco nos extenderemos aquí en el análisis de la otra clásica estrategia incriminatoria de la víctima, por lo general va asociada con la anterior, centrada en el pretendido "desenmascaramiento" dela pertenenciaideológica yla memoria combativa de los estudiantes ruralistas manifiestamente auto-identificados con las consignas y los valores de la guerrilla revolucionaria de los años setenta, cuyo más célebre dirigente fue un maestro ruralista, Lucio Cabañas, egresado precisamente de la Escuela Rural de Ayotzinapa. A medida que pasa el tiempo y disminuye o se diluye el impacto del acontecimiento, esta versión incriminatoria -basada en argumentos ideológicos- persistente, nunca explícitamente desactivada, se filtra y reaparece bajo la modalidad de la hipótesis, del rumor, las presuposiciones, de la alusión velada, sosteniendo en el fondo el ideologe$m a^{3}$ que postula una relación lógico-causal entre las ideas "subversivas" de las víctimas y las consecuencias "naturales" o "lógicas" de sus acciones, abonando así la hipótesis aberrante del castigo merecido.

\section{EL ETHOS HUMANITARIO. RETÓRICA DE LA CONDESCENDENCIA}

No recuerdo una noticia de primera plana que me haya impactado tanto en lo personal como el destino que parecen haber tenido los estudiantes de Ayotzinapa. Esta vez no hablo como reportero, soy un padre de familia tengo tres hijos, el más grande tiene ocho años; quizá alguno de ellos de joven se vuelva activista y un buen díallega a casa y me anuncie que se va a una manifestación en favor delo que sea sería hasta genéticamente explicable y por eso me duele muchísimo lo de Ayotzinapa.

¿Qué clase de país es este donde protestar contra una pareja de políticos criminales impresentables puede costar que te secuestren, te asfixien, te quemen durante 14 horas, te maten a balazos, trituren a batazos los restos de tus huesos, te embolsen y te avienten a un río? Desde el viernes que se presentaron los testimonios de los delincuentes y las fotografías que respaldan sus dichos, como nunca estoy triste, descuadrado, indignado hasta la rabia. Creo que es la peor tragedia del último medio siglo, es una brutalidad comparable sólo con la Alemania nazi, en México, ciertamente nada tan grave de la represión del ' 68 y el '71 y me parece que el gobierno no debe dar a este expediente el trato de cualquier otro escándalo porque este es el más terrible de todos los escándalos (...) Hace unos días en la televisión por la mañana entrevisté a don Rafael López Catarino, papá de Julio César, uno de los chavos; pocas veces me han dado ganas de llorar durante el noticiario, una de esas fue cuando me contó que un día Julio César le dijo que lo acompañara a comprar unos zapatos y resulta que la sorpresa, los zapatos eran para él, para Don Rafael. Y los llevaba puestos, me los mostró, y me dijo que aunque estuvieran viejitos y medio rotos, no se los iba a quitar y que con esos zapatos está buscando a su hijo y con esos zapatos lo iba a encontrar vivo. Escucharlo me pegó en el alma (...) Lo único que pienso es en los zapatos de Don Rafael; pienso en mis hijos y nunca quiero estar calzado en esos zapatos. Gracias por escuchar este comentario ${ }^{4}$.

3 Según Angenot, los ideologemas son proposiciones reguladoras, "máximas ideológicas que corresponderían a prácticas sociales particulares" o, por el contrario, (como en el caso que nos ocupa) que poseen un alcance muy general "hasta el punto de parecer corresponder a reglas antropológicas universales" (1982, pp. 27-43).

4 Video-comentariodelperiodistaCarlosLoretdeMola. Recuperadodehttps://www.youtube.com/watch?v=7t9n29FrG3w 
Este video archivado en YouTube ${ }^{5}$ es particularmente complejo por su factura retórica. Tratándose de un soporte audiovisual, juegan aquí un papel decisivo los significantes corporales del ethos: la gestualidad, el tono de la voz ("embargada") y particularmente la mirada a cámara ("empañada"), algo que Verón (1983) señaló como un recurso fundamental en el establecimiento del contacto con el interlocutor, según el eje "ojos en los ojos". Definimos el ethos humanitario como una estrategia de construcción de la imagen del enunciador basada en una supuesta "esencia de lo humano", prescindiendo de toda determinación histórica, política, económica, de género. Se trata de una operación simetrizante, siguiendo a Amossy (2000), basada en una igualación entre enunciador y enunciatario en la común condición esencial de seres humanos y padres de familia.

El procedimiento de igualación involucra no sólo al enunciador y al enunciatario, sino también a un tercero en cuestión que ocupa en el discurso el lugar de víctima. Siempre, según Amossy, la igualación entre las víctimas y los alocutarios se funda en el tópico del sufrimiento de los inocentes y en la similitud fundamental que une a todos los hombres en la humana condición: el sufrimiento y la muerte. Añade la autora que la distancia que separa a aquellos de los que se habla (las víctimas) y los interactuantes se encuentra disminuida al máximo por la insistencia en una humanidad común. Desde nuestro punto de vista, el ethos humanitario es el fundamento de una retórica de la condescendencia que marca el "tono" predominante en el texto, sobre todo en otro fragmento particularmente ambiguo en que el enunciador se refiere a los estudiantes:

Es cierto que los ayotzinapos, como les dicen a los estudiantes allá, secuestraban camiones, vandalizaban oficinas, bloqueaban carreteras y lanzaban bombas molotov. Pero esos delitos no se pagan con la desaparición ni el asesinato. Es verdad que no eran unas blancas palomas, pero también es cierto que su pobreza, su histórica marginación y falta de oportunidades los convertía en jugosa carne de cañón, en débiles víctimas de quienes quisieran lucrar con ellos ${ }^{6}$.

La condescendencia es un dispositivo asimétrico deenunciación basado en relaciones desiguales de poder: el sujeto que ejercela condescendencia se ubica en una posición de superioridad (a menudo algún tipo de autoridad) respecto de un destinatario colocado, a su vez, en posición de inferioridad. Según Bourdieu (1985) la condescendencia consiste en "una forma de negación simbólica de las relaciones objetivas de poder” (1985, p. 107).

Por efecto de la estrategia de la condescendencia, la supuesta propensión delictiva de los estudiantes y el "vandalismo" que se les adjudica, indi-

5 Elvideo es el comentario, a título personal, de un periodista de la empresa monopólica Televisa, a menudo señalada por su postura acrítica frente al gobierno mexicano.

6 Video-comentario del periodista Carlos Loret de Mola. Recuperado de https:/www.youtube.com/ watch? $=7$ t9n 29 FrG $3 \mathrm{w}$ 
rectamente, resultan disminuidos en su gravedad, todo como efecto de la mirada indulgente que los adultos destinarían a la "pasajera rebeldía" de los jóvenes. Cliché, este último, muy arraigado y socorrido en el discurso de la doxa, según el cual ciertas condiciones atribuidas a los jóvenes, "idealismo", "romanticismo", "el deseo de justicia", fueran "males pasajeros, atributos "naturales" -casi biológicos- de la juventud, que se superan con los años y la experiencia.

\section{LOS FRACASOS DEL ETHOS}

Seplantea aquíla cuestión delo que el mismo Maingueneau (2010) define en términos de los "fracasos del ethos", advirtiendo además que éstos son moneda corriente "ya que el ethos que se busca no necesariamente es el ethos producido" (2010, p. 208). En términos de Verón (1987), es en la instancia de reconocimiento -en su desfase constitutivo respecto de la instancia de producción- donde podrá finalmente comprobarse el éxito o el fracaso, el rechazo o la aceptación, del ethos propuesto en el acto de enunciación. El ethos sería asíla prenda de una apuesta que queda supeditada a la aceptación o ala invalidación del destinatario.

En los ejemplos que siguen, seleccionados del sistema de comentarios suscitados por las declaraciones del periodista en el video antes analizado, se presenta una típica situación de fracaso del ethos en la instancia de reconocimiento: en primer lugar, se produce un desmontaje de la operación básica del ethos humanitario que consiste, como ya mencionamos, en el despojamiento retórico por parte del sujeto de la enunciación de su investidura y de su pertenencia, ya sea oficial, institucional o empresarial, a fin de presentarse "simplemente" como un "ser humano", un padre de familia condolido ${ }^{7}$. Las réplicas del sistema decomentarios, algunos de fuerte tono insultante, descomponen esa operación poniendo en evidencia la pertenencia empresarial al monopolio mediático (Televisa) y la conocida filiación política del periodista y de la empresa que representa: el ethos humanitario resulta erosionado en sus mismos fundamentos. Tanto la condolencia comola enfática indignación resultan impugnadas, como puede verse en los dos comentarios siguientes, transcritos en su literalidad y escogidos al azar entre el corpus disponible:

Si realmente estás impactado, no lo publiques en Youtube donde tu sabes no existe impacto, tu mismo en un reportaje hablaste de que internet representa menos del $5 \%$ de la opinión pública. Tu que tienes el poder de la televisión. HAZ ALGO!! (...) La gente que vivimos en Internet ya abrimos los ojos, los que tienen que abrir los ojos es la gente que solo ve la Televisión. Mientras no hagas cosas serias en televisión. Este tipo de videos colgados de youtube me parecen una burla.

7 Vale precisar que aquí no está en discusión ni nos corresponde pronunciarnos acerca de la eventual sinceridad o falsedad de las palabras del sujeto en cuestión, quien por definición carece de nombre propio.

(1)

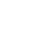


C...., no entiendo tu «indignacion» pues trabajas para una empresa que fabrico a ese INEPTO Presidente, Junto con todos los «comentaristas» de Televisa (...) a ocultar informacion que pueda perjudicar a EPNy atacan con todo a los politicos que no son de agrado de el jefe ...o y no es nuevo pues en realidad siempre han hecho lo mismo sin importar COLORES, IDEOLOGIAS, Y MUCHAS VECES CON PASADOS TURBULENTOS LLENOS DE CORRUPCION+ Tal ves ? como padre te pueda doler el dolor de esa gente $<$ Pero siempre se antepondra tu criterio mercantilista y mercenario en tu trabajo ${ }^{8}$.

\section{El polémico video mereció también una contundente respuesta por parte de Anonymus:}

Hola, que tal mexicanos y mexicanas. En esta ocasión vengo a desmentir el infame video que publicó el señor... sobre el caso de Ayotzinapa. Es una vergüenza que quieran disfrazar con montajes la verdad de nuestro pueblo (...) Sinceramente me disculpo con mi auditorio, pero este vídeo es una farsa total: ¿Que no es usted el encargado de montar los techos de las noticias que más afectan al país? ¿Que no fue usted el único periodista en montar las primeras imágenes del caso Ayotzinapa? Me pregunto, ¿usted cree que alguien le va a creer, si usted es el autor intelectual de la censura en México? Mexicanos no se dejen engañar, las palabras de este señor son hipócritas, ahora bien él nos dice que está cansado de las autoridades mexicanas (...) Contestaré a su pregunta señor: la clase de país que tenemos y vivimos es justamente lo contrario a lo que usted difunde en sus noticieros. Es un país con miles de personas desempleadas, es un país con un índice elevado de delincuencia, es un país corrupto, es un país desigual, es un país donde las televisoras, sí, su televisora, manipula las noticias y la información: esta es la clase de país en la que vivimos ${ }^{9}$.

\section{CONSIDERACIONES FINALES}

Las estrategias de conjura del acontecimiento constituyen en conjunto unos procedimientos retóricos, narrativos y enunciativos destinados a producir efectos de verosimilitud mediante una conversión general al régimen de la doxa, respetandolosideologemas ylos entimemas, los estereotipos yloslugares comunes en que dicho régimen se asienta, lo que la retórica antigua identificaba bajo el concepto de tópica. La tópica, precisa Angenot:

Produce lo opinable, lo plausible, pero también está presupuesta en toda secuencia narrativa, constituye el orden de la veridicción consensual que es condición de toda discursividad, y que sostiene la dinámica de encadenamiento de los enunciados de todo tipo y entraña los presupuestos propios de una determinada época y sociedad (2010, p. 5).

8 La ortografía y otros aspectos gramaticales de la cita no fueron corregidos y se mantienen según el texto original.

9 Ídem. Video recuperado de https://www.youtube.com/watch? $\mathrm{v}=\mathrm{xYSxpLOPso \& ebc=ANyPxKr6Y7aqRVlKhtNP}$ ZgCz24U53fu53y8KZNxLoUwZLRtFrxeDI5vkQ3xcuS2VF4d5P0QB70_mcW_OakNN7T-xDI66Sbwiiw 
Según esta definición, el procedimiento de verosimilización del acontecimiento consiste en producir unos relatos creíbles y aceptables, que gocen de consenso mayoritario y que se ajusten a los principios y valores de la doxa. En el horizonte de una ética del acontecimiento, Badiou (1999) establece una distinción crucial entre la ética de una verdad y, por el contrario, una ética de la comunicación: “Toda verdad depone los saberes constituidos y, en consecuencia, se opone a las opiniones, ya que se llama opiniones a las representaciones sin verdad, los desechos anárquicos de un saber circulante" (1999, p. 131). Luego agrega:

\footnotetext{
La comunicación es apropiada únicamente para las opiniones; en todo lo que concierne a las verdades se requiere que haya encuentro... De repente la ética de una verdad es todo lo contrario de una ética dela comunicación (...) La ética de una verdad se opone de manera absoluta a la opinión y a la ética a secas, que no es más que un esquema de opinión (1999, p. 132).
}

Por definición, el acontecimiento, y particularmente el que aquí nos interpela bajo el nombre de Ayotzinapa, es irreductible e incompatible con el régimen de la opinión y los principios de verosimilitud en que ésta se sostiene. En otros términos, se define como un exceso, y una falta, que no puede ser asimilado ni procesado según la tópica ni los presupuestos de la doxa, siendo un núcleo de interrogantes suspendidos, que no cesan de interpelarnos en espera de respuesta: ¿Qué está ocurriendo en este preciso momento?, ¿Qué nos está sucediendo?, ¿Cuál es el mundo, el período, este preciso momento en el que estamos viviendo? 


\section{REFERENCIAS}

Amossy, R. (2000). L'argumentation dans le discours. París, France: Nathan.

Angenot, M. (1982). La Parole pamphletaire. Contribution a la typologie des discours modernes. Paris: Payot.

Angenot, M. (1989). Un etat du discours social. Québec: Le Preambule.

Angenot, M. (2010). El discurso social. Problemática de conjunto. Buenos Aires: Siglo XXI.

Badiou, A. (1999). El ser y el acontecimiento. Buenos Aires: Manantial.

Bitonte, M. (2007, octubre). Tres aportes a la noción de operaciones: Verón, Fisher, Goodman. En Figuraciones. Teoría y crítica de artes, 6, pp. 1-14 (versión online). Recuperadodehttp://www.revistafiguraciones.com.ar/numeroactual/recorrido. php?idn $=6 \&$ idr $=45$

Bourdieu, P. (1985). ¿Qué significa hablar? Economía de los intercambios lingüísticos. Madrid: Akal.

Derrida, J. \& Stiegler, B. (1998). Ecografías de la televisión. Entrevistas filmadas. Buenos Aires: EUDEBA.

Foucault, M. (1995). Discurso, Poder y Subjetividad. Buenos Aires: El cielo por asalto.

Foucault, M. (2009). La verdad y las formas jurídicas. Barcelona: Gedisa.

Foucault, M. (2004). Discurso y verdad en la antigua Grecia. Barcelona: Paidós.

Foucault, M. (2004). El orden del discurso. Buenos Aires: Tusquets.

Foucault, M. (1987). Historia de la sexualidad. La voluntad de saber. Buenos Aires: Siglo XXI.

Foucault, M. (1979). Nietzsche, la genealogía, la historia. En Microfísica del poder (pp. 7-29). Madrid: La Piqueta.

Maingueneau, D. (2010). El enunciador encarnado. La problemática del Ethos. En Versión, 24, 203-225.

Maingueneau, D. (2002, Junio). Problèmes d'ethos. En Pratiques, 113/114, 55-67.

Nora, P. (1985). La vuelta del acontecimiento. En J. Le Goff y P. Nora (compiladores) Hacer la historia (pp. 221-239). Barcelona: Laia.

Tabachnik, S. (1999). Palabrasguardadas. Víctimas, sobrevivientes ytestigos. En Estafeta 32,0 , pp. 25-28. 
Tabachnik, S. (2006, segundo semestre). Anonimato, enunciación y verdad en las comunidades virtuales. Cosas dichas entre lo público y lo privado. En Revista Latinoamericana de Ciencias de la Comunicación 5 (3), pp. 26-35.

Tabachnik, S. (2014, mayo-agosto). Voces clandestinas en la red. Aproximación a las estrategias del narcodiscurso. En Revista Argumentos, 75(27), pp. 103-116.

Verón, E. (1987). La semiosis social. Fragmentos de una teoría de la discursividad. Barcelona: Gedisa.

Verón, E. (1983). Il est là, je le vois, il me parle. En Communications, 38, pp. 98-120.

Verón, E. (1987). Construir el acontecimiento. Buenos Aires: Gedisa.

\section{IDENTIFICACIÓN DE LA AUTORA}

Silvia Tabachnikes Doctora en Ciencias Sociales y miembro del Sistema Nacional de Investigadores de México. Se desempeña como Profesora Investigadora en la Universidad Autónoma Metropolitana de la Ciudad de México, desarrollando tareas investigativas en el campo de los estudios del lenguaje y de la comunicación social. Es fundadora y dirigió, entre 1991-2001, la Maestría en Sociosemiótica del Centro de Estudios Avanzados de la Universidad Nacional de Córdoba, Argentina. Ha publicado dos libros: Voces sin nombre. Confesión y testimonio en la escena mediática (1995) y Lenguaje y juegos de escritura en la red. Una incursión por las comunidades virtuales (2012), además de numerosos artículos en libros y revistas internacionales.

\section{REGISTRO BIBLIOGRÁFICO:}

Tabachnik, S. (2016, diciembre). La construcción del acontecimiento en la era de Internet. En InMediaciones de la Comunicación, 11, pp. 181-195. Revista de la Escuela de Comunicación, Facultad de Comunicación y Diseño, Universidad ORT Uruguay, República Oriental del Uruguay. 